\title{
Discriminating quantity: new starting points for teaching children with Down syndrome about number?
}

Article

Accepted Version

Porter, J. (2019) Discriminating quantity: new starting points for teaching children with Down syndrome about number? International Journal of Disability, Development and Education, 66 (2). pp. 133-150. ISSN 1034-912X doi:

https://doi.org/10.1080/1034912X.2019.1569208 Available at https://centaur.reading.ac.uk/81779/

It is advisable to refer to the publisher's version if you intend to cite from the work. See Guidance on citing.

To link to this article DOI: http://dx.doi.org/10.1080/1034912X.2019.1569208

Publisher: Taylor \& Francis

All outputs in CentAUR are protected by Intellectual Property Rights law, including copyright law. Copyright and IPR is retained by the creators or other copyright holders. Terms and conditions for use of this material are defined in the End User Agreement.

www.reading.ac.uk/centaur 
Central Archive at the University of Reading

Reading's research outputs online 


\title{
Discriminating Quantity: New starting points for teaching children with Down syndrome about number?
}

\begin{abstract}
The focus of much mathematics teaching has been on the acquisition of counting, an area where children with Down syndrome can experience particular difficulties. Research with typically developing children has highlighted how early awareness of quantity provides a strong platform for the acquisition of later mathematical skills and programmes of early intervention have been introduced. Many of these studies are embedded in the work and traditions of developmental and cognitive psychology and can be difficult to access. Consequently, this is an area that has been largely ignored in the curricula of children with Down syndrome. This paper seeks to make this literature more available. It systematically reviews previous research with children with Down Syndrome on these early foundations. It considers seemingly contradictory findings in the light of differences in tasks, their presentation and instructions, and the responses required, in order to draw conclusions and reflect on the implications for teaching and learning. Some of these propositions are in contrast to existing practices and call for further research to test their effectiveness.
\end{abstract}

Key Words: Down Syndrome; early mathematics; quantity; numerosity; object tracking system; approximate number system

\section{Introduction}

In a seminal review paper, Lemons, Powell, King and Davidson (2015) found that mathematics interventions that had been formally evaluated with children with Down syndrome (DS), were largely undifferentiated from those more generally employed with children with intellectual disability. In part this reflects a divide in the literature with much research on Down syndrome undertaken by psychologists investigating the nature of their cognitive difficulties in order to gain broader insights into the functioning of the brain. Other research has been concerned with the nature of mathematical understanding and makes a distinction between the acquisition of skills of counting, and the underlying understanding of what it means to count. Taken together these research studies have suggested that many children with DS experience particular difficulty learning to count, and that too much emphasis is placed on trying to teach children skills that they find challenging rather than finding other avenues for developing mathematical understanding. This paper sets out to explore the possibility of building on skills that usually develop before the acquisition of language - namely that of being able to discriminate between quantities. First we set this within the context of some of the difficulties or challenges faced by children with DS and summarize the nature of early mathematical development. We review what is currently known about the skills of children with DS in this area and explore the implications for teaching and learning. 


\section{Background}

Rochel Gelman has been particularly influential in the understanding of young children's mathematical skills. She reached a conclusion that, whereas typically developing children were guided in their acquisition by an implicit understanding of the principles of counting, children with DS children learned to count by rote (Gelman 1982). A further study by Gelman and Cohen (1988) set out to confirm this view. Children with DS, unlike their mainstream peers, were largely unable to use their understanding in a novel counting task (where children are asked to start counting pointing to a designated object), despite being given hints. We must be cautious about this conclusion, the two groups were not matched on equivalent cardinal tasks, two of the group of eight did as well or better than their matched peers, and as Brigstocke, Hulme and Nye (2008) note the language used for the task was complex. These limitations were addressed in a study by Caycho, Gunn and Siegler (1991) who found no differences in the performance of children with DS matched to typically developing children on receptive language on a similar task but where the language was simplified. However, the nature of the task makes a difference. Author (1999) compared children's ability to count with their ability to spot errors made by a puppet and found that competence in counting was not entirely matched by conceptual understanding. Even though there were children in her sample that could count accurately, they could not spot errors made by the puppet, with the exception of two pupils who spotted cardinality errors. Further, no child who couldn't count accurately could detect errors, suggesting that the ability to count comes before the understanding. This pattern has also been found in typically developing children on an identical task (Author 1998). In a review of research, Abdelhameed (2007) concluded that many children with Down syndrome experience difficulties in counting and the evidence points to the role of language and memory; a similar conclusion to a later review by King, Powell, Lemons and Davidson (2017) and consistent with the experiences of Noda and Bruno (2017) and Abreu-Mendoza and Aria-Trejo (2017). Abdelhameed (2007) also however questioned whether a further factor was the lack of a rich counting environment coupled with low teacher expectations.

\section{Difficulties that Impact on Counting}

There is a growing body of evidence that the difficulties experienced by at least some children with Down syndrome lie in the production of a stably ordered count string (Caycho et al 1991; Author 1999; Nye, Fluck \& Buckley 2001; Charitki, Baralis, Polychronopoulou, Lappas \& Soulis 2014). While children with DS may be able to say as many number words as their matched aged peers, they don't produce them in a stably ordered list. Instead they recycle parts of the number string, skip parts or use a mixture of the two strategies. In consequence when they count and recount they find a different number of items, impeding an understanding of the cardinal value of the set and what it 
means to count. In contrast children show better performances in relation to 1:1 correspondence, assigning one numberword to each item. Traditionally, children learn the number string as an auditory sequential memory task, repeating numbers they hear, often at the beginning as a "chant" (Fuson 1988). Thus, with repetition each number becomes associated with the next number. This can be challenging for children with Down syndrome who have a shorter memory span for digits than children of a similar mental age (Hulme \& McKenzie 1992; Seung \& Chapman 2000; Godfrey \& Lee 2018).

There is also a further possibility, that attentional difficulties underlie poor performance as Zimpel (2013; 2016) has found, children with Down syndrome experience difficulty attending to more than one object at a time. In a study of 176 people with DS, Zimpel (2016) found that mistakes were rarely made at identifying that this was a group of 1 or 2 items, but less than half were able to identify a group of 4 . They appeared to be unable to mentally file 4 items. Further, young people with DS who could not count perceived lines of 3 and 4 dots as identical in a computer game. In Zimpel's words they have a "smaller scope of attention" (Zimpel 2016 p145).

In summary children with DS appear to experience difficulties in the acquisition and understanding of counting. The role of attention, memory and language has been implicated. Unstable performance on counting tasks can impact on a conceptual understanding of number that underpins later arithmetic and functional skills. There is however a further way of examining the foundations of mathematical development which is the focus of this article.

\section{Early Mathematical Development}

Research with typically developing children has identified their awareness of quantity from an early age. Numerical properties (or numerosity) are highly salient for them, providing information that enables young children to tailor their actions to the number of items and later utilize this information in problem solving. This research is particularly relevant to children with Down syndrome as it concerns skills that are demonstrated well before children develop the language of number.

Infants as young as 5 months old are able to identify the incorrect solutions to addition and subtraction involving 1, 2 and 3 objects, but not 4 (Wynn 1992; Berger 2006). When for example, they see two items and a screen is put up before a third item is added, they are surprised when the screen is removed and only one item is seen. By 9 months infants have been found to identify correct and incorrect solutions to adding and subtracting items of 5+5 and 10-5 (McCrink \&Wynn 2004). These studies all use infant looking time as an indicator of whether the outcome is surprising (as they look longer at novel events) or not. Active responses can be elicited in the case of older infants. By 14.5 months of age infants actively look for the number of 1,2 or 3 items they have seen hidden, 
completing their hunt when they have successful found the exact number (Fiegenson \& Carey 2003). Fiegenson and colleagues in a study of children's choice of containers of crackers, found that the way that items are presented impacts on children's mental representations. Infants were successful in choosing between two containers when they saw the items placed successively in one cup and then the comparison set placed in a second cup. Children failed the task if items were alternately hidden in the two locations, as children appeared to be unable to update their mental representations of number (Fiegenson \&Yamaguchi 2009). This highlights the need to be mindful of the way tasks are presented and the impact on working memory.

Psychologists have suggested that two cognitive processes may underpin numerical representation (summarized in Figure 1). One that is employed by young infants involves tracking individual objects so that each is mentally filed separately, (object object) rather than represented as a group of two or three (Sella, Berteletti, Lucangeli \& Zorzi 2016). It is this process (the object tracking system or OTS) that enables the infants in Wynn's study to be surprised when the screen was removed only one object was revealed. Like the children in Zimpel's study, they also cannot mentally file 4 items. With the OTS, representation is precise (Mou \& van Marle 2014; Sella, et al 2016). However, infants also demonstrate further abilities, this time with larger quantities. At 6 months they can discriminate between dot arrays, such as 8 versus 16 dots, but not 8 versus 12 (Carey $\&$ Xu 2001). This is not limited to visual items, as children also demonstrate these skills when presented with different numbers of sounds in these ratios (Lipton \& Spelke 2003). With these larger numbers the limitation is not determined by absolute quantity, but about the ratio between the two presentations. By 11 months infants demonstrate an understanding of the ordinal relationship between 4, 8 and 16 dots (Brannon 2002). With age children are able to make finer discriminations and are successful with smaller ratios. Three year olds discriminate between arrays that vary in the ratio of 3:4 dots and 6 year olds succeed on tasks involving ratios of 5:6 and some (but not all) adults with ratios of 10:11 (Halberda \& Fiegenson 2008; Piazza et al 2010).

\section{INSERT Figure 1 about here}

The cognitive processes that underpin the discrimination of larger numbers is referred to in the literature as the approximate number system (ANS). The key feature is that discrimination varies according to the ratio between the quantities presented. In contrast to the OTS, the representation of number is approximate. Both the ANS and OTS appear to contribute to mathematical development in different ways. The OTS system has been argued as the phenomenon subitizing (Ansari \& KarmiloffSmith 2002; Sella et al 2016) and the ANS "a putative numberline" (Sella et al 2016 p2). There is some disagreement about the extent to which these operate as two entirely distinct systems (Cordes \& Brannon 2009; Cantlon, Platt \& Brannon 2009; Leibovitch, Katzin, Harel \& Henik 2016) as the ANS 
can also make judgements about small quantities. One (largely) uncontested conclusion however is that from a young age numerosity is a salient cue, one that is used to anticipate, make predictions and support problem solving. It provides a tool for making comparisons, for knowing there is more or less, and for estimation. A number of studies have found these early skills to predict later mathematical ability (Libertus, Fiegenson \& Halberda, 2011; Bonny \& Lourenco 2013; Fazio, Bailey, Thompson \& Siegler 2014; Wang, Odic, Halberda \& Feigenson 2016; Peng, Yang \& Meng 2017), suggesting that if we can boost these abilities we provide children with a stronger foundation for mathematical learning. It is therefore important to investigate these skills in children with Down syndrome.

\section{Review Strategy}

This paper turns now to review what research has revealed in relation to these early abilities in children with Down syndrome. It is driven by the following research question:

What do we know about the ability of children with DS to discriminate quantities? More specifically we ask:

How do researchers present these tasks?

How do children with DS respond and how does this compare with typically developing children?

What are the implications for teaching and learning?

The inclusion criteria for this review were studies that provide empirical data on participants with DS, on tasks requiring discrimination between quantities that were written for peer review journals in English. Although much of the literature has been undertaken by developmental and cognitive psychologists, we were mindful that mathematics educators might also report on these tasks. We employed a number of strategies to systematically identify relevant literature. First key databases were identified: Psychoinfo; Child Development \& Adolescent Studies; BEI; ERIC; and Web of science. We searched using key words: Down Syndrome/Trisomy 21 together with the specific terms: numerosity; magnitude; ANS; ONS; OTS; subitizing and we also used the broader terms of counting, enumeration, estimation and mathematics together with parameters of publication between 20002018. Titles and abstracts of articles were read to exclude articles that utilized these key-words in a non-mathematical context. This yielded some 64 articles (including duplicates) of which 8 studies met the explicit criteria. Citations of these papers and their references were examined to ensure we had not missed additional material. These studies are outlined in Table 1 indicating key aspects of their findings and their methodology

Insert table 1 here

\section{Findings}


The studies provide data on a broad range of participants ranging in age from 12 months to 35 years potentially providing insights about children pre and post education. All but one study (Author 2018; submitted) compares performance with those of typically developing children matched for mental age and chronological age. These studies are underpinned by the question of whether children with DS are simply delayed, and perform as the matched MA groups or if they experience specific and significant differences and if so what is the nature of these discrepancies. The presence of a matched chronological age group signifies recognition that these abilities may also be related to experience. The studies by Paterson and colleagues compare performance to children with William syndrome, a group of children with a contrasting profile who despite their cognitive difficulties, unlike children with DS, have relative strengths in verbal ability. A comparison between these two groups potentially indicates the role of verbal skills in the acquisition of different number tasks. Author (2018; submitted) makes no direct comparison with other groups of children but examines the relative strengths of children with Down syndrome across set size and ratio.

The age distribution across the studies leads to important differences in the ways that the tasks are designed and the responses that participants are expected to make. Habituation studies (such as those used by Paterson and colleagues) are deployed with infants using a measure of looking time, which, as we have noted, is known to be longer to novel displays. In this way children demonstrate their ability to discriminate between familiar numerosities and new ones. Looking time has the advantage of allowing a fine grain measure to analyze differences between children. Unusually, AbreuMendoza and Arias-Trejo (2015) also use looking time following the instruction "which is larger", with a group of participants with a mean age of 12 years. Other studies require participants to point or depress a key, in the case of Sella et al (2013) one button to indicate "the same" and another for "different." This request is rather different from the instruction to point to "which is more" (e.g. Belacchi et al 2014; Author submitted ) or "which is larger" (e.g. Paterson 2001) or to say if they " belong to the same family" (Camos 2009). Lanfranchi et al (2015) ask "where the number has to be" placed on a number line. While this task also investigates the precision with which children can discriminate between two numbers it does so in a very different way. Children are required to translate the spoken number to a linear representation and map the number in an approximate way. A further difference between the other studies concerns whether comparisons are made using simultaneous presentations (side by side), as for example in the studies of Belacchi et al (2014) Abreu-Mendoza \& Arias-Trajo (2015), Author (2018; submitted) and Paterson Girelli, Butterworth and Karmiloff-Smith (2006) with the adult task; or sequential, where one array is presented and then disappears as in the studies of Sella, Lanfranchi and Zorzi (2013); Camos (2009) and the infant studies of Paterson and colleagues $(2001 ; 2006)$. 
The demands on participants therefore vary across tasks and studies. Further, studies that require children to respond rather than look, translate into a considerable number of presentations. For example, participants completed 72 trials in the study of Paterson et al (2006) and 108 in the study of Sella et al (2013). In order to preclude the possibility that children use counting, presentation times are short, set sizes are more often larger and children have to respond quickly. In consequence a number of children in some studies fail to meet criterion performance and are excluded from the study (e.g. Paterson et al 2006; Sella et al 2013). This can have significant consequences when the group is already small in number, and heterogeneous in relation to chronological and mental age. This review of findings must therefore consider the extent to which performance is adversely effected by task demands and the impact on different sub-groups within the population of children with DS. These concerns are partly offset by larger studies such as those by Belacchi et al (2014) which involved 42 young people with DS and that of Author (2018; submitted) with 47 participants. This most recent study did not use strict timing criteria nor automated presentations, responding to concerns that the design of studies could jeopardise our knowledge of the capabilities of the full group of children with Down syndrome.

These methodological differences may help to explain some of the ambiguities in the findings. Paterson (2001) concluded that her infants had "an impairment" as they were unable to discriminate 2 from 3. In 2006 together with her colleagues she drew the conclusion that they were "seriously delayed". However, the adults in her study responded with a typical trajectory, although these data are limited to the performance of 7 young people as 2 did not complete the task. The study by Camos (2009) on the one hand confirm the difficulty with discriminating between ratios of 2:3 as her children did not perform significantly above chance on this ratio, but surprisingly neither did the matched MA or CA group. This raises the question of whether her "same family task" proved to be a robust assessment. The findings contrast to those of Sella et al (2013) in which the young people with DS performed worse on the trials involving the ratios 2:3 and 3:4 compared to the MA matched group. They were slower to respond and therefore had more missing responses. As a result 7 of the 21 were excluded from the study. This study highlights the challenge for some children of tasks requiring fast responses and to some extent reflects the findings of Belacchi et al (2014) who used large set sizes and required responses within 4 seconds where children with DS also did worse than the matched MA group on discriminating "which has more". Interestingly however they outperformed the matched MA group when the task involved addition, which the authors ascribe to their longer school experience. These five studies appear to lead us to a conclusion that, taking into account the methodological constraints, children with DS are significantly delayed in performance on these numerosity tasks. 
Other evidence suggests that we should cautious in reaching this conclusion. The following studies both involved discrimination of numerosity using simultaneous rather than sequential presentations. The study by Abreu-Mendoza and Arias-Trejo (2015) found no significance differences between the performance of 16 young people with DS and a matched MA group in discriminating numerosity or area. Numerosity tasks used set sizes of 4-36 objects and were presented in ratios of 1:3 1:2;2:3 and 3:4 and measured eye tracking rather than requiring children to point or pressing a lever. Author (2018; submitted) also using simultaneous presentations, did not compare her participants to typically developing children, but found that they did follow the expected trajectory of decreasing performance with decreasing ratio. Two aspects are of note in her study. Firstly $42 \%$ of the older group (mean CA 13.7 years) were able to discriminate arrays that differed up to and including the ratio of 5:6. The literature has suggested that this is usually attained around the age of 6 years. In the young group (mean CA 8.8 years) children performed better with large sets than with small sets. This is consistent with the findings of Paterson and colleagues $(2001 ; 2006)$ and with Sella et al (2013) who also found poor performance with small set sizes.

Finally turning to the study of Lanfranchi and colleagues who investigated children's estimation skills requiring children to place numbers on a numberline of $0-10$ or $0-100$, they found that children with DS's skills were in line with their MA for the smaller set size task but outperformed the matched MA typically developing children on the 0-100 task which could indicate the greater role of experience in facilitating estimation skills.

In summary the findings are consistent with the overall view that:

- children with DS follow the pattern of acquisition of typically developing children with some children able to make discrimination between arrays that vary in the ratio of 5:6;

- their performance is sensitive to aspects of the methodology leading to some participants being excluded from the studies;

- there is some evidence that performance on discrimination tasks involving large set sizes is better than performance using small set sizes;

We turn to consider the implications of set size on performance, firstly from a theoretical point to view and secondly the implications for teaching.

\section{Explanations for Children's responses}

As we have already discussed the literature suggests that two different processes underpin the discrimination of numerosity, the discrimination of 1,2,3 and possibly 4 rests on the object file system (OTS) where items are mentally represented individually. In contrast, larger set sizes of 5 or more 
items are represented by the approximate number system (ANS). Mou and van Marhle (2014) have helpfully used the metaphor of whether one sees the forest (represented by the ANS) or the trees (filed by the OTS). Using these distinctions, the evidence suggests that children with Down syndrome experience difficulty forming individual representations for small numbers of objects in order that comparisons can be made. This is consistent with the view of Zimpel (2016) of the limitation to attention and that of Brodeur, Trick, Flore, Marr and Burack (2013) who report children's difficulty in tracking more than a single object. In contrast performance on large number sets require less sustained attention as they can be formed in relation to density.

There are alternative explanations for children's difficulties in these studies with small set sizes which should be considered. To create individual object files requires visual discrimination of distinct entities. Children with Down syndrome have been found to experience a number of visual difficulties. As Little, Woodhouse, Lauritzen and Saunders (2007) state "Even with fully corrected refractive errors and in the absence of manifest abnormalities, children with DS have reduced visual acuity compared with their developmentally healthy peers". P3995. This will impact on their performance on visual discrimination tasks. Studies do not routinely assess children's vision, assuming that this will be corrected through wearing glasses where necessary. Thus, one explanation for the difference lies with the acuity of children's vision. This would particularly impact on young infants as in Paterson's 2001/2006 study as improvements in visual acuity occur over the first two years. A second explanation is one of interference from previous learning. Although speed of presentation typically prevents counting it doesn't necessarily preclude responding with a number label- especially if that is what one has been taught to do. This may interfere with the request to find the one which is "more," which may then seem nonsensical. Further studies are clearly needed to test out these different explanations.

There is a greater degree of agreement in the reviewed studies that the approximate number system of children with DS is relatively in tact, (although we should be mindful of the heterogeneity within and across the samples). This gives impetus to considering how we might build on this ability to perceive differences to support children's arithmetic abilities. A number of studies provide evidence to suggest a relationship between the ability to discriminate quantities and later success on arithmetic tasks. Chu, van Marle and Geary (2015) for example suggest that the ANS supports children's understanding of cardinality; Wang et al (2016) that it supports early arithmetic. It is argued that the ANS supports children in the process of mapping number words onto their mental representation and this enables an understanding of cardinality (Libertus 2015) and later arithmetic procedures such as counting on when adding numbers. Other authors go further in outlining the role of the ANS. Siegler \& LortieForgues, (2014) provide a model of mathematical development in which the representation of 
magnitude lies at the core, supporting the development of increasingly precise representations and the shift from non-symbolic to symbolic representations. More broadly the contribution of the ANS has been argued to contribute to the confidence with which children recognize unlikely solutions, to provide an underlying sense of number (Libertus et al 2016) a "gut sense" of number (Wang et al 2016). Indeed this has led to a number of pre-school intervention programmes that set out to improve the ANS such as "Number Race" (Wilson, Revkin, Cohen, Cohen, \& Dehaene 2006; Wilson, Dehaene, Dubois \& Fayol 2009) and "Preschool Number Learning Scheme (PLUS)" ( Van Herwegen, Costa, Passolunghi 2017). Notably the relationship between the ANS and the development of arithmetic skills appears to be stronger in typically developing children before the age of 6 years than after (Fazio et al 2014).

\section{Implications for Teaching}

The literature on typically developing children therefore suggests that for at the early stages of learning about number we should support the ability to discriminate between quantities, rather than placing so much emphasis on the acquisition of the number string and counting (Clarke \& Faragher 2014). Our analysis of current research with children with DS suggests that this might best be done initially using large sets. This is a departure from much maths teaching where the focus is on small quantities, where for example children are introduced to 1,2 and 3. The research reviewed here suggests that this practice may be introducing some children with Down syndrome to number using the most difficult starting point. Further, Author (2018), found that it necessary when developing an ipad game to alter the starting point for choosing between numerosities from ratios of 1:2 and 1:3 to 1:4 with large sets. This echoes studies with typically developing children. In a series of studies Odic, Hock, and Halberda (2014) demonstrated the negative impact on children's performance of being presented with hard discriminations first, children not only performed badly on these tasks but also on subsequent easy discrimination tasks. In contrast the 5 year old children who were given the easier tasks first performed extraordinarily well, discriminating arrays that varied in the ratio 12:14. This was not seen to be related to interest or practice but rather to their confidence in the task. This issue of progression is particularly important with respect to children with Down syndrome who, in the face of difficulty, lose interest (Agheana \& Duta 2013) or deploy locational strategies (Wishart 2001; Author 2018).

The literature also suggests a departure from reliance on presentations that are based on structured arrays, where children may learn to label patterns rather than attend to quantities. Further work by Chan and Mazzocco (2017) draws attention to the way in which additional cues, such as colour, compete for attention with quantity in numerosity tasks both for children and adults. This suggests that with children with DS we use single colours in each discrimination task. It does not however mean that we have to restrict tasks to mechanical presentation of repeated dot presentations, rather 
that we think how we can build these non-symbolic discriminations into everyday activities. We might for example use dot notations to indicate numerical contents of jars, boxes or drawers.

Alternatively, Siegler and Ramani (2009) have drawn attention to the important role of board games in fostering understanding of thecounting sequence. Their research with pre-schoolers has highlighted the benefit of playing on a linear track compared to a circular one resulting in better scores on magnitude comparisons, estimating skills and addition. Children who took part in their study were almost all able to count to ten so we might plan an initial adaptation for children with DS. Instead of using a spinner or dice with fixed patterns in these games, the child might choose from two groups of counters, including one that exceeds 4 in number that are place out on the board. These counters could be clear so that players can see the numbers printed on each circle or square. Using a large ratio of 1:4 or 1:5 will encourage the child to select the group which is more to place out until the final destination is reached and one person wins.

In addition to board games we can introduce quantity into everyday activities where numerosity, rather than a number label or word serves as a cue, for example in locating a drawer or cupboard. We should not confine our activities to vision but consider also how sound and quantity can serve as a cue. The evidence from studies with typically developing children together with some early day findings with children with DS (Tuset, Bruno \& Noda 2016) suggests that intervention can be beneficial, but it's apparent that we need robust research to be conducted to evaluate the effectiveness of this additional approach and the place of random rather than structured presentations of quantity. Research has repeatedly indicated the variation in performance on mathematics tasks (Herrara et al 2011; Agehana and Duta 2013) and it's important that our approach is individually tailored to specific profiles.

\section{Conclusion}

There are many reasons to suggest that we do not simply rely on the development of children's counting skills to provide the foundation for later arithmetic skills. Children with DS's difficulty with the acquisition of the number string and the consequent impact on their understanding of what it means to count suggest that we should consider alternative approaches. Repeated exposure to hard tasks can have a demoralising effect. Research has demonstrated that numerical properties are salient to young children and that awareness of differences in quantity underpins some aspects of later mathematical development. Children with DS also appear to respond favourably to tasks involving discrimination of large quantities and follow the expected pattern of increasing refinements in their discrimination. There is however evidence to suggest that they experience difficulty with these tasks when small numbers are used. 
While the research literature has tested children using tightly controlled presentations, teachers need to think creatively about the deployment of quantity as a cue in the environment, so that there is a purpose and an interest in attending to quantity. There is also a place for games, board games, card games and computer games. In devising these approaches we need, as the literature has indicated, to be mindful of the demands on attention, memory, and language.

There is a need for more research, specifically to understand changes over time, and the effectiveness of intervention with this group of young people. The review of studies reveals the heterogeneity of responding, and it is important that in addition to looking at group responses we also pay attention to individual differences. We cannot rule out the possibility that there are individuals with DS who, as with their mainstream peers, experience particular difficulties. This review raises important methodological issues about the way in which research has been conducted. There is a particular role for research that does not require fast responses to time sensitive presentations. In addition to risking the danger of under-representing children's abilities there are also ethical issues of undermining children's confidence. Further research in this area will enable us to provide the right level of challenge. Overall this review has suggested that we can be cautiously optimistic about incorporating awareness of quantity in teaching of mathematics.

Funding Details: This review has not been funded

Disclosure Statement: No financial interest or benefit has arisen from the application of this research.

\section{References}

Author 1998,

Author 1999;

Author 2018.

Author (submitted)

Abdelhameed H. (2007) Do Children with Down Syndrome Have Difficulty in Counting and Why? International Journal of Special Education, 22, 2 129-139.

Abreu-Mendoza, R.A., \& Arias-Trejo, N. (2015) Numerical and Area Comparison Abilities in Down Syndrome. Research in Developmental Disabilities, 41-42 58-65. doi:10.1016/j.ridd.2015.05.008.

Abreu-Mendoza, R. A., \& Arias-Trejo, N. (2017). Counting ability in Down syndrome: The comprehension of the one-to-one correspondence principle and the role of receptive vocabulary. Neuropsychology, 31(7), 750-758. doi.org/10.1037/neu0000377

Agheana, V., \& Duta, N. (2015) Achievements of Numeracy Abilities to Children with Down Syndrome: Psycho-Pedagogical Implications. Procedia-Social and Behavioural Sciences 186, 38-45. doi.org/10.1016/j.sbspro.2015.04.068 
Ansari, D., \& Karmiloff-Smith, A. (2002). Atypical trajectories of number development: A neuroconstructivist perspective. Trends in Cognitive Sciences, 6, 511-516.

Belacchi, C., Passolunghi, M. C., Brentan, E., Dante, A., Persi, L., \& Cornoldi, C. (2014). Approximate additions and working memory in individuals with Down syndrome. Research in Developmental Disabilities, 35, 1027-1035. doi: 10.1016/j.ridd.2014.01.036

Berger, A., Tzur, G. Posner, M.I. (2006) Infant brains detect arithmetic errors. Proceedings of the National Academy of Sciences 103 (33) 1264912653; DOI:10.1073/pnas.0605350103

Bonny, J. W., \& Lourenco, S. F. (2013). The Approximate Number System and its Relation to Early Math Achievement: Evidence from the Preschool Years. Journal of Experimental Child Psychology, 114, 3, 375-388. http://doi.org/10.1016/j.jecp.2012.09.015

Brannon, E.M. (2002) The development of ordinal numerical knowledge in infancy, Cognition, 83, 3, 223-240.

Brigstocke, S., Hulme, C., \& Nye J. (2008) Number and arithmetic skills in children with Down syndrome. Down Syndrome Research and Practice online DOI 10.3104/reviews/2070.

Brodeur, D., Trick, L., Flore H., Marr C., \& Burack, J. (2013) Multiple-object tracking among individuals with Down syndrome and typically developing children. Development and Psychopathology, 25,2, 545-553. doi: 10.1016/j.ridd.2014.01.036.

Camos, V. (2009). Numerosity discrimination in children with Down syndrome. Developmental Neuropsychology, 34, 435-447. doi: 10.1080/87565640902964557

Cantlon, J. F., Platt, M. L., \& Brannon, E. M. (2009). Beyond the Number Domain. Trends in Cognitive Sciences, 13, 2, 83-91. http://doi.org/10.1016/j.tics.2008.11.007

Carey, S., \& Xu, F. (2001). Infants' knowledge of objects: Beyond object files and object tracking. Cognition, 80, 179-213.

Caycho, L., Gunn, P., \& Siegal, M. (1991). Counting by children with Down syndrome. American Journal on Mental Retardation, 95, 575-583.

Chan, J. Y. C., \& Mazzocco, M. M. M. (2017). Competing features influence children's attention to number. Journal of Experimental Child Psychology, 156, 62-81. DOI: 10.1016/j.jecp.2016.11.008

Charitaki, G., Baralis G., Polychronopoulou S., Lappas D., Soulis G.S. (2014) Early Numeracy in Children with Down's Syndrome in Greece. Psychology 5, 1426-1432. DOI:

10.4236/psych.2014.512153

Chu, F.W. van Marle K., \& Geary D.C, (2015) Early Numerical Foundations of young children's mathematical development. Journal of Experimental Child Psychology 132, 205-212. 
Clarke B., \& Faragher R. (2014) Developing Early Number Concepts for Children with Down Syndrome. Chapter 6 in R. Faragher \& B. Clarke (Eds) Educating Learners with Down Syndrome. London: Routledge.

Cordes, S., \& Brannon, E. M. (2009). Crossing the Divide: Infants Discriminate Small From Large Numerosities. Developmental Psychology, 45, 6, 1583-1594. doi.org/10.1037/a0015666

Fazio, L.K. Bailey, D.H., Thompson, C.A. \& Siegler, R.S. (2014) Relations of different types of numerical magnitude representations to each other and to mathematics achievement, Journal of Experimental Child Psychology, 123, 53-72, . doi: 10.1016/j.jecp.2014.01.013

Feigenson, L., \& Carey, S. (2003). Tracking individuals via object-files: Evidence from infants' manual search. Developmental Science, 6, 568-584. doi/10.1111/1467-7687.00313

Feigenson, L. and Yamaguchi, M. (2009), Limits on Infants' Ability to Dynamically Update Object Representations. Infancy, 14, 244-262.

Fuson K., C. (1988) Children's Counting and Concepts of Number. Springer- Verlag: New York.

Gelman R. (1982) Basic numerical abilities. In R.J. Sternberg (Ed) Advances in the Psychology of Intelligence, 1 181-205.

Gelman R., \& Cohen M. (1988) Qualitative Differences in the way Down syndrome and normal children solve a novel counting task. In L.Nadel (Ed) The Psychobiology of Down Syndrome. M.I.T.: Mass.

Godfrey, M., \& Lee, N. R. (2018). Memory profiles in Down syndrome across development: a review of memory abilities through the lifespan. Journal of Neurodevelopmental Disorders, 10, 5. doi.org/10.1186/s11689-017-9220-y

Halberda, J., \& Feigenson, L. (2008). Developmental change in the acuity of the "number sense": The approximate number system in 3-, 4-, 5-, and 6-year-olds and adults. Developmental Psychology, 44, 1457-1465. doi: 10.1037/a0012682

Herrera, A.N. A. Bruno, A., González, C., Moreno L., \& Sanabria, H. (2010). Addition and subtraction by students with Down syndrome. International Journal of Mathematical Education in Science and Technology, 42, 1,13-35, DOI: 10.1080/0020739X.2010.500698

Hulme, C. and Mackenzie, S. (1992) Working Memory and Severe Learning Difficulties. Hove: Lawrence Erlbaum Associates

King, S.A. Powell, S.R. Lemons, C.J. \& Davidson, K.A. (2017) Comparison of Mathematics Performance of Children and Adolescents with and without Down Syndrome. Education and Training in Autism and Developmental Disabilities, 52, 2, 208-222

Lanfranchi, S., berteletti, I., Torrisis, E., Vianello R., \& Zorzi M. (2015) Numerical estimation in individuals with Down syndrome. Research in Developmental Disabilities, 36, 222-229. 
Leibovich, T., Katzin, N., Harel, M. and Henik, A. (2016) 'From "sense of number" to "sense of magnitude" - The role of continuous magnitudes in numerical cognition', Behavioral and Brain Sciences, 40, e164 1-62. doi: 10.1017/S0140525X16000960.

Lemons, C.J. Powell, S.R., King, S.A. \& Davidson, K.A. (2015) Mathematics interventions for children and adolescents with Down syndrome: a research synthesis. Journal of Intellectual Disability Research 59, 767-783. doi: 10.1111/jir.12188

Libertus M.E. (2015) The Role of Intuitive Approximation Skills for School Math Abilities. Mind Brain and Education. 9, 2, 112-120. doi.org/10.1111/mbe.12072

Libertus, M. E., Feigenson, L., \& Halberda, J. (2011). Preschool acuity of the approximate number system correlates with school math ability. Developmental Science, 14, 1292-1300. doi.org/10.1111/j.1467-7687.2011.01080.x

Libertus, M. E., Odic, D., Feigenson, L., \& Halberda, J. (2016). The Precision of Mapping Between Number Words and the Approximate Number System Predicts Children's Formal Math Abilities. Journal of Experimental Child Psychology, 150, 207-226. doi: 10.1016/j.jecp.2016.06.003

Lipton, J. S., \& Spelke, E. S. (2003). Origins of number sense: Large number discrimination in human infants. Psychological Science, 14, 396-401 DOI:10.1111/1467-9280.01453

Little, J., Woodhouse, Joy Margaret, Lauritzen, J. S. and Saunders, K. J. 2007. The impact of optical factors on resolution acuity in children with Down Syndrome. Investigative Ophthalmology and Visual Science 48 (9) , pp. 3995-4001. DOI:10.1167/iovs.06-1387

McCrink, K., \& Wynn, K. (2004). Large-number addition and subtraction by 9-month-old infants. Psychological Science, 15, 776-781. DOI: 10.1111/j.0956-7976.2004.00755.x

Mou Y., \& van Marle K. (2014) two core systems of numerical representation in infants. Developmental Review 34, 1-25. doi.org/10.1016/j.dr.2013.11.001

Noda A., \& Bruno A. (2017) Assessment of the Knowledge of the Decimal Number System Exhibited by Students with Down Syndrome. Qualitative Research in Education, 6,1, 56-85.

doi.org/10.17583/qre.2017.2061

Nye., J., Fluck, M. \& Buckley S. (2001) Counting and Cardinal Understanding in Children with Down syndrome and typically developing children. Down Syndrome, Research and Practice, 7, 6878.

Odic, D. Hock, H. \& Halberda, J. (2014) Hysteresis affects approximate number discrimination in young children. Journal of Experimental Psychology. General 2014 Volume: 143 Issue: 1, Page: 255265 doi: $10.1037 / \mathrm{a} 0030825$

Paterson S. (2001) Language and Number Development in Down Syndrome. Down Syndrome Research and Practice 7, 2 77-86. 
Paterson, S. J., Girelli, L., Butterworth, B., \& Karmiloff-Smith, A. (2006). Are numerical impairments syndrome specific? Evidence from Williams syndrome and Down's syndrome. Journal of Child Psychology and Psychiatry, 47, 190-204. DOI:10.1111/j.1469-7610.2005.01460

Peng, P. Yang, X. Meng, X. (2017) The relation between approximate number system and early arithmetic: The mediation role of numerical knowledge, Journal of Experimental Child Psychology, 157, 111-124. . doi: 10.1016/j.jecp.2016.12.011

Piazza, M., Facoetti, A., Trussardi, A. N., Berteletti, I., Conte, S., Lucangeli, D., ... Zorzi, M. (2010). Developmental trajectory of number acuity reveals a severe impairment in developmental dyscalculia. Cognition, 116, 33-41. doi: 10.1016/j.cognition.2010.03.012.

Sella, F. , Berteletti, I. , Lucangeli, D. and Zorzi, M. (2016), Spontaneous non- verbal counting in toddlers. Developmental Science, 19, 329-337. doi:10.1111/desc.12299

Sella, F., Lanfranchi, S., \& Zorzi, M. (2013). Enumeration skills in Down syndrome. Research in Developmental Disabilities, 34, 3798-3806. DOI:10.1016/j.ridd.2013.07.038

Seung, H.K., \& Chapman, R. (2000) Digit span in individuals with Down syndrome and in typically developing children: temporal aspects. J. Speech Lang Hear Res. 43, 3, 609-20.

Siegler, R.S. \& Lortie-Forgues, H. (2014) An Integrative Theory of Numerical Development. Child Development Perspectives, 8, 3, 144-150 doi.org/10.1111/cdep.12077

Siegler, Robert S.,Ramani, Geetha B. (2009) Playing linear number board games - but not circular ones-improves low-income preschoolers' numerical understanding. Journal of Educational Psychology, 101, 3, 545-560. doi.org/10.1037/a0014239

Tuset, I; Bruno, A.; Noda, A. (2016) Subitizing in numerical tasks with Down syndrome children in Macias, JA; Jimenez, A; Gonzalez, JL; et al. (Ed) Conference: 20th Annual Symposium of the Spanish-Society-of-Research-in-Mathematical-Education (SEIEM) Univ Malaga, Fac Educ Sci, Malaga, SPAIN Date: SEP 08-10, 2016 INVESTIGACION EN EDUCACION MATEMATICA XX Investigacion en Educacion Matematica p649-649

Van Marle, K., Chu, F.W. Mou, Y., Seok, J.H. Rouder J., \& Geary, D.C. (2018) Attaching meaning to the number words: contributions of the object tracking and approximate number systems Developmental Science 21(1). doi.org/10.1111/desc.12

Van Herwegen, J. Costa H.M. \& Passolunghi, M.C. (2017) Improving Approximate Number Sense Abilities in Preschoolers: PLUS Games. School Psychology Quarterly 32, 4, 497-508.

DOI: $10.1037 / \mathrm{spq} 0000191$

Wang J.J, Odic D, Halberda J, Feigenson L. (2016) Changing the precision of preschoolers' approximate number system representations changes their symbolic math performance. Journal of Experimental Child Psychology 147, 82-99. doi.org/10.1016/j.jecp.2016.03.002

Wilson, A. J., Dehaene, S., Dubois, O., \& Fayol, M. (2009). Effects of an adaptive game intervention on accessing number sense in low-socioeconomic- status kindergarten children. Mind, Brain and 
Education: The Official Journal of the International Mind, Brain, and Education Society, 3, 224-234. doi.org/10.1111/j.1751-228X.2009.01075.x

Wilson, A. J., Revkin, S. K., Cohen, D., Cohen, L., \& Dehaene, S. (2006). An open trial assessment of "The Number Race," an adaptive computer game for remediation of dyscalculia. Behavioral and Brain Functions, 2, 20. doi.org/10.1186/ 1744-9081-2-20

Wishart J. (2001) Motivation and Learning Styles in Young Children with Down Syndrome. Down Syndrome Research and Practice, 72 47-51. DOI:10.3104/reports.113

Wynn, K. (1992). Addition and subtraction by human infants. Nature, 358, 749-750.

DOI: $10.1038 / 358749 \mathrm{a} 0$

Zimpel, A.F. (2013) Studies towards a better understanding of learning disabilities in case of trisomy 2. Report on the results of a preliminary study (German) fur Neuropsychologie 24, 1, 35-47.

Zimpel, A.F. (2016) Trisomy 21. What we can learn from people with Down syndrome. Gottingen: Vandenhoeck \& Ruprech. 